\title{
Multi-Target Cytotoxic Actions of Flavonoids in Blood Cancer Cells
}

\author{
Katrin Sak*, Hele Everaus
}

\begin{abstract}
To date, cytotoxic effects of flavonoids in various cancer cells are well accepted. However, the intracellular signaling cascades triggered by these natural compounds remain largely unknown and elusive. In this minireview, the multiplicity of molecular targets of flavonoids in blood cancer cells is discussed by demonstrating the involvement of various signaling pathways in induction of apoptotic responses. Although these data reveal a great potential of flavonoids for the development of novel agents against different types of hematological malignancies, the pleiotropic nature of these compounds in modulation of cellular processes and their interactions certainly need unraveling and further investigation.
\end{abstract}

Keywords: Natural flavonoids - blood cancer cells - cytotoxic action - multi-targeted signaling - reactive oxygen species

Asian Pac J Cancer Prev, 16 (12), 4843-4847

\section{Introduction}

The anticancer properties of flavonoids as plant secondary metabolites constituting an important part of the human diet are currently well accepted. Such activities include growth inhibitory effects, blocking the progression of cell cycle and inducing the death of malignant cells. At that, apoptosis or type I programmed cell death is the most common mechanism of chemotherapeutic as well as chemopreventive action of flavonoids (Baumann et al., 2008; Park et al., 2015). There are currently more than 5000 structurally different flavonoids and various molecular mechanisms can be underlying the cytotoxic effects exerted by these compounds in different cancer cells, including also blood cancer cells (Lu et al., 2007; Britschgi et al., 2010; Lanoue et al., 2010; Malyanto et al., 2012; Righeschi et al., 2012; Liu et al., 2015). Modulation of multiple cellular signaling processes by acting simultaneously on different molecular targets makes flavonoids novel attractive candidates for chemotherapy allowing to eradicate malignant cells and delay also the emergence of drug resistance (Spagnuolo et al., 2011; Benelli et al., 2012; Spagnuolu et al., 2012). However, the exact mechanisms by which flavonoids induce their cytotoxic activities in leukemia, lymphoma and myeloma cells have remained largely unclear and require certainly further investigation (Lu et al., 2007; Britschgi et al., 2010; Budhraja et al., 2012; Feng et al., 2012; Yuan et al., 2012). In this short communication, we present a brief overview of molecular targets of flavonoids in malignant blood cells and discuss the importance of such pleiotropic action in view of the development of novel antileukemia, antilymphoma and antimyeloma agents.

\section{Multiple Targets of Flavonoids in Blood Cancer Cells}

The proapoptotic activity of different flavonoids (the most common of them and more extensively studied: quercetin, fisetin, galangin, kaempferol, morin, myricetin, apigenin, luteolin, baicalein, wogonin, naringenin, genistein, as well as green tea catechins) in various blood cancer cells is related to the downregulation of antiapoptotic proteins, including $\mathrm{Mcl}-1, \mathrm{Bcl}-2, \mathrm{Bcl}-$ $\mathrm{XL}$, and XIAP; and activation of proapoptotic proteins, including Bax, Bad, and Bid, cleavage of PARP and release of mitochondrial cytochrome $\mathrm{c}$ into the cytosol (see Figure 1) (Lee et al., 2002; Li et al., 2004; Ko et al., 2005; Shieh et al., 2006; Tolomeo et al., 2008; Han et al., 2009; Jin et al., 2009; Budhraja et al., 2012; Ghorbani et al., 2012; Switalska et al., 2013; Baran et al., 2014; Chen et al., 2015; Lee WS et al., 2015; Park et al., 2015). The generated imbalance in the expression of anti- and proapoptotic proteins increases the susceptibility of malignant cells to apoptotic signals and flavonoids induce apoptosis mostly through the caspase-dependent pathways, whereas both the mitochondrial (intrinsic) apoptotic cascade as well as death receptor-mediated (extrinsic) signaling can be activated (Ma et al., 2005; Lee et al., 2006; Lu et al., 2007; Lee et al., 2011; Chen et al., 2013).

Induction of cellular death pathways by flavonoids is often accompanied by the modulation of activity of different protein kinases (Figure 1); however, the exact mechanisms underlying these signaling cascades are still elusive and depend both on the certain flavonoids as well as the types of leukemia cells. In this respect, genistein is able to activate MAPKp38 and AMPK involved in 


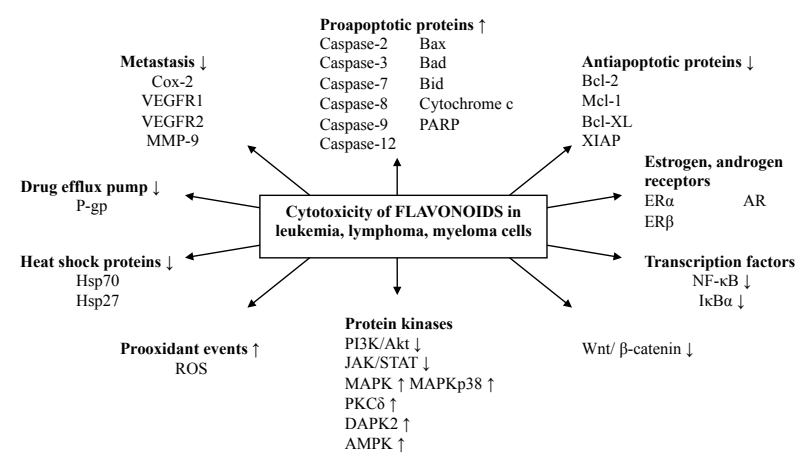

Figure 1. Pleiotropic Cytotoxic Activity of Flavonoids in Malignant Blood Cells. (Akt, protein kinase B; AMPK, AMP-activated protein kinase; AR, androgen receptor; Bad, $\mathrm{Bcl}-2$-associated death promoter; Bax, Bcl-2-associated X protein; Bcl-2, B-cell lymphoma 2; Bcl-XL, B-cell lymphomaextra large; Bid, BH3 interacting-domain death agonist; Cox-2, cyclooxygenase 2; DAPK2, death-associated protein kinase 2; ER, estrogen receptor; Hsp, heat shock protein; $\mathrm{I} \alpha \mathrm{B} \alpha$, nuclear factor of kappa light polypeptide gene enhancer in B-cells inhibitor; JAK, Janus kinase; MAPK, mitogen-activated protein kinase; Mcl-1, myeloid cell leukemia 1; MMP-9, matrix metalloproteinase 9; NF-kB, nuclear factor $\varkappa \mathrm{B}$; PARP, poly(ADP-ribose) polymerase; P-gp, P-glycoprotein; PI3K, phosphatidylinositol-4,5-bisphosphate 3-kinase; PKC, protein kinase C; ROS, reactive oxygen species; STAT, signal transducer and activator of transcription; VEGFR, vascular endothelial growth factor receptor; XIAP, X-linked inhibitor of apoptosis protein)

the apoptotic processes in U937 promonocytes and some other human leukemia cell lines (Sanchez et al., 2008). Also, quercetin can activate AMPK leading to the caspase-3-dependent apoptosis in HL-60 promyelocytes (Xiao et al., 2014). Green tea catechin EGCG enhances the programmed cell death signaling through an increase in DAPK2 protein in HL-60 and NB4 promyelocytes (Britschgi et al., 2010), while PKC $\delta$ represents a key player in apigenin-induced apoptotic response in THP-1 monocytes (Vargo et al., 2006). One of the major targets of apigenin seems to be also the JAK/STAT pathway that is downregulated in both myeloid as well as erythroid leukemia cells (Ruela-de-Sousa et al., 2010; De Martino et al., 2011).

Several blood cancer cells have shown to exert the characteristic of elevated level of phosphorylated Akt compared to their normal counterparts (Bortul et al., 2005; Yuan et al., 2012). Inhibition of PI3K/Akt pathway can play a crucial role in the apoptotic processes caused by multiple flavonoids in different blood cancer cells: by apigenin, quercetin and baicalin in HL-60 promyelocytes (Ruela-de-Sousa et al., 2010; De Martino et al., 2011; Yuan et al., 2012; Zheng et al., 2012); by quercetin, kaempferol, chrysin and deguelin in U937 promonocytes (Bortul et al., 2005; Ramos et al., 2008; Marfe et al., 2009; Khoo et al., 2010); by quercetin in chronic lymphocytic leukemia cells (Russo et al., 2014); by kaempferol, oroxylin A and wogonin in K562 myelogenous leukemia cells (Marfe et al., 2009; Wang et al., 2014; Xu et al., 2014); by baicalin in CA46 Burkitt lymphoma cells (Huang et al., 2012); by naringenin in THP-1 monocytes (Park et al., 2008); and by xanthohumol in several acute lymphocytic leukemia cells (Benelli et al., 2012). These flavonoids can behave as Akt inhibitors inducing the programmed cell death and may therefore have a strong potential as novel anticancer agents in the treatment of some hematological neoplasms.

Downstream of Akt, the constitutively higher activity of NF-kB can also be implicated in malignant transformation, whereas several flavonoids, like baicalein, deguelin and genistein are able to suppress the activity of this molecule (Chen et al., 2006; Otsuyama et al., 2007; Benelli et al., 2012; Yamasaki et al., 2013).

One important signaling cascade in cytotoxic responses triggered by flavonoids is considered to be the Wnt pathway that is blocked by quercetin in some leukemia cells like DND-41 T-lymphoblasts (Kawahara et al., 2009); however, these mechanisms are still rather poorly understood. Similarly, the involvement and precise role of several other molecular targets in flavonoidsinduced cellular death, including estrogen and androgen receptors (Yamasaki et al., 2010; Sak et al., 2015), but also the heat shock proteins (Wei et al., 1994; Shen et al., 2008; Gonzalez-Mejia et al., 2010) definitely need further investigation (Figure 1).

Moreover, as depicted in Figure 1, flavonoids cannot only inhibit the proliferation of malignant cells and induce their death, but these compounds may also suppress the metastatic processes by modifying the interactions between blood cancer cells and the surrounding microenvironment (Benelli et al., 2012). For instance, several green tea catechins have shown to inhibit the expression of MMP-9, Cox-2 or VEGF receptors in different myeloid and lymphoid leukemia cells, being linked to suppression of inflammatory and angiogenetic processes and impeding thus the migration and invasion of neoplasms (Annabi et al., 2007; Angelo et al., 2009; Vezina et al., 2012; Harakeh et al., 2014).

\section{ROS-dependent and -independent cytotoxicity}

Among various mechanisms reported for the cytotoxic action of flavonoids (Figure 1), these compounds might exert their anticancer properties also through the prooxidant events, by promoting intracellular ROS generation (Sergediene et al., 1999; Ueda et al., 2001; Chen et al., 2004). Although flavonoids are generally known as antioxidants, they can act as prooxidants under certain conditions and the mitochondrial dysfunction pathway mediated by production of ROS is considered to play a pivotal role in the onset of cell death in several blood cancer cells. Indeed, the ROS increase is involved in apoptosis induction by quercetin, morin, tamarixetin, baicalein and baicalin in HL-60 promyelocytes (Wang et al., 1999; Wang et al., 2004; Kuo et al., 2007; Lu et al., 2007; Sakao et al., 2009a; Sakao et al., 2009b; Nicoloni et al., 2014); by quercetin in MOLT-4 lymphocytes (MertensTalcott et al., 2005); by baicalin in Jurkat T cells (Ueda et al., 2001); by EGCG in NB4 and UF-1 promyelocytes (Nakazato et al., 2005); and by eupatorin in some myeloid and lymphoid leukemia cells (Estevez et al., 2014).

However, the induction of programmed cell death can also occur independently on ROS production and this is reported even for the same flavonoids in similar cellular 
context. On this point, quercetin has shown to trigger apoptosis in HL-60 promyelocytes also independently on its prooxidant effects (Shen et al., 2003) and myricetin, fisetin, casticin, wogonin, naringenin and hesperetin can also induce cytotoxic responses in HL-60 promyelocytes without promotion of ROS levels (Lee et al., 2002; Chen et al., 2003; Ko et al., 2005; Morales et al., 2012; Kikuchi et al., 2013). These somewhat contradictory data still need unraveling and the involvement of ROS in apoptotic machinery requires further clarification.

\section{Conclusions and prospects}

Numerous published reports clearly indicate that flavonoids can serve as novel therapeutic agents for treatment of different types of hematological malignancies. However, their signaling pathways in blood cancer cells have still remained elusive and it is evident that better understanding of the molecular targets and cellular mechanisms involved in the cytotoxic action of these natural compounds may contribute to the development of molecularly-targeted therapy for leukemia, lymphoma and myeloma. Simultaneous modulation of different signal transduction pathways can also be important to overcome the problems related to emergence of chemoresistance.

It is well known that flavonoids occur in the human diet in various combinations, whereas individual compounds interact with different molecular targets and simultaneously influence different intracellular signaling cascades. Therefore, the complex effects of bioactive constituents may reflect their synergistic action and this fact makes flavonoids especially attractive on view of the chemopreventive strategies. In the future, it would be tempting to study some of these combinations also from the therapeutic aspects to avoid the recurrence of different blood cancers and improve the patients` quality of life.

\section{References}

Angelo LS, Kurzrock R (2009) Turmeric and green tea: a recipe for the treatment of B-chronic lymphocytic leukemia. Clin Cancer Res, 15, 1123-5.

Annabi B, Currie JC, Moghrabi A, Beliveau R (2007) Inhibition of HuR and MMP-9 expression in macrophage-differentiated HL-60 myeloid leukemia cells by green tea polyphenol EGCg. Leuk Res, 31, 1277-84.

Baran I, Ionescu D, Filippi A, et al (2014) Novel insights into the antiproliferative effects and synergism of quercetin and menadione in human leukemia Jurkat T cells. Leuk Res, 38, 836-49.

Baumann S, Fas SC, Giaisi M, et al (2008) Wogonin preferentially kills malignant lymphocytes and suppresses T-cell tumor growth by inducing PLCgamma1- and Ca2+dependent apoptosis. Blood, 111, 2354-63.

Benelli R, Vene R, Clarlo M, et al (2012) The AKT/NF-kB inhibitor xanthohumol is a potent anti-lymphocytic leukemia drug overcoming chemoresistance and cell infiltration. Biochem Pharmacol, 83, 1634-42.

Bortul R, Tazzari PL, Billi AM, et al (2005) Deguelin, a PI3K/ AKT inhibitor, enhances chemosensitivity of leukaemia cells with an active PI3K/AKT pathway. Br J Haematol, 129, 677-86.

Britschgi A, Simon HU, Tobler A, Fey MF, Tschan MP (2010)
Epigallocatechin-3-gallate induces cell death in acute myeloid leukaemia cells and supports all-trans retinoic acid-induced neutrophil differentiation via death-associated protein kinase 2. Br J Haematol, 149, 55-64.

Budhraja A, Gao N, Zhang Z, et al (2012) Apigenin induces apoptosis in human leukemia cells and exhibits antileukemic activity in vivo. Mol Cancer Ther, 11, 132-42.

Chen FY, Cao LF, Wan HX, et al (2015) Quercetin enhances adriamycin cytotoxicity through induction of apoptosis and regulation of mitogen-activated protein kinase/extracellular signal-regulated kinase/c-Jun N-terminal kinase signaling in multidrug-resistant leukemia K562 cells. Mol Med Rep, 11, 341-8.

Chen J, Kang J, Da W, Ou Y (2004) Combination with watersoluble antioxidants increases the anticancer activity of quercetin in human leukemia cells. Pharmazie, 59, 859-63.

Chen WH, Chen Y, Cui GH (2006) Deguelin inhibits expression of IkappaBalpha protein in Raji and U937 cells. Acta Pharmacol Sin, 27, 485-90.

Chen YC, Shen SC, Lin HY (2003) Rutinoside at C7 attenuates the apoptosis-inducing activity of flavonoids. Biochem Pharmacol, 66, 1139-50.

Chen YJ, Wu CS, Shieh JJ, et al (2013) Baicalein triggers mitochondria-mediated apoptosis and enhances the antileukemic effect of vincristine in childhood acute lymphoblastic leukemia CCRF-CEM cells. Evid Based Complement Alternat Med, 2013, 124747.

De Martino L, DArena G, Filosa R, et al (2011) Natural compounds in anti-leukaemic therapy: a review. Mini Rev Med Chem, 11, 492-502.

Estevez S, Marrero MT, Quintana J, Estevez F (2014) Eupatorininduced cell death in human leukemia cells is dependent on caspases and activates the mitogen-activated protein kinase pathway. PLoS One, 9, 112536.

Feng Y,Zhang S, Tu J, et al (2012) Novel function of scutellarin in inhibiting cell proliferation and inducing cell apoptosis of human burkitt lymphoma namalwa cells. Leuk Lymphoma, 53, 2456-64.

Ghorbani A, Nazari M, Jeddi-Tehrani M, Zand H (2012) The citrus flavonoid hesperidin induces p53 and inhibits NF-kB activation in order to trigger apoptosis in NALM-6 cells: involvement of PPAR $\gamma$-dependent mechanism. Eur J Nutr, 51, 39-46.

Gonzalez-Mejia ME, Voss OH, Murnan EJ, Doseff AI (2010) Apigenin-induced apoptosis of leukemia cells is mediated by a bimodal and differentially regulated residue-specific phosphorylation of heat-shock protein-27. Cell Death Dis, 1,64 .

Han DH, Jeong JH, Kim JH (2009) Anti-proliferative and apoptosis induction activity of green tea polyphenols on human promyelocytic leukemia HL-60 cells. Anticancer Res, 29, 1417-21.

Harakeh S, Diab-Assaf M, Azar R, et al (2014) Epigallocatechin3-gallate inhibits tax-dependent activation of nuclear factor kappa B and matrix metalloproteinase 9 in human T-cell lymphotropic virus-1 positive leukemia cells. Asian Pac J Cancer Prev, 15, 1219-25.

Huang Y, Hu J, Zheng J, et al (2012) Down-regulation of the PI3K/Akt signaling pathway and induction of apoptosis in CA46 Burkitt lymphoma cells by baicalin. J Exp Clin Cancer Res, 31, 48.

Jin CY, Park C, Lee JH, et al (2009) Naringenin-induced apoptosis is attenuated by Bcl-2 but restored by the small molecule Bcl-2 inhibitor, HA 14-1, in human leukemia U937 cells. Toxicol In Vitro, 23, 259-65.

Kawahara T, Kawaguchi-Ihara N, Okuhashi Y, et al (2009) Cyclopamine and quercetin suppress the growth of leukemia 
and lymphoma cells. Anticancer Res, 29, 4629-32.

Khoo BY, Chua SL, Balaram P (2010) Apoptotic effects of chrysin in human cancer cell lines. Int J Mol Sci, 11, 2188-99.

Kikuchi H, Yuan B, Yuhara E, Takagi N, Toyoda H (2013) Involvement of histone $\mathrm{H} 3$ phosphorylation through p38 MAPK pathway activation in casticin-induced cytocidal effects against the human promyelocytic cell line HL-60. Int J Oncol, 43, 2046-56.

Ko CH, Shen SC, Hsu CS, Chen YC (2005) Mitochondrialdependent, reactive oxygen species-independent apoptosis by myricetin: roles of protein kinase $\mathrm{C}$, cytochrome $\mathrm{c}$, and caspase cascade. Biochem Pharmacol, 69, 913-27.

Kuo HM, Chang LS, Lin YL, et al (2007) Morin inhibits the growth of human leukemia HL-60 cells via cell cycle arrest and induction of apoptosis through mitochondria dependent pathway. Anticancer Res, 27, 395-405.

Lanoue L, Green KK, Kwik-Uribe C, Keen CL (2010) Dietary factors and the risk for acute infant leukemia: evaluating the effects of cocoa-derived flavanols on DNA topoisomerase activity. Exp Biol Med, 235, 77-89.

Lee TJ, Kim OH, Kim YH, et al (2006) Quercetin arrests G2/M phase and induces caspase-dependent cell death in U937 cells. Cancer Lett, 240, 234-42.

Lee WJ, Chen YR, Tseng TH (2011) Quercetin induces FasLrelated apoptosis, in part, through promotion of histone $\mathrm{H} 3$ acetylation in human leukemia HL-60 cells. Oncol Rep, 25, 583-91.

Lee WR, Shen SC, Lin HY, et al (2002) Wogonin and fisetin induce apoptosis in human promyeloleukemic cells, accompanied by a decrease of reactive oxygen species, and activation of caspase 3 and $\mathrm{Ca}(2+)$-dependent endonuclease . Biochem Pharmacol, 63, 225-36.

Lee WS, Yun JW, Nagappan A, et al (2015) Flavonoids from Orostachys japonicus A. Berger induces caspase-dependent apoptosis at least partly through activation of p38 MAPK pathway in U937 human leukemic cells. Asian Pac J Cancer Prev, 16, 465-9.

Li YC, Tyan YS, Kuo HM, et al (2004) Baicalein induced in vitro apoptosis undergo caspases activity in human promyelocytic leukemia HL-60 cells. Food Chem Toxicol, 42, 37-43.

Liu X, Ye, F, Wu J, et al (2015) Signaling proteins and pathways affected by flavonoids in leukemia cells. Nutr Cancer, $\mathbf{6 7}$, 238-49.

Lu HF, Hsueh SC, Ho YT, et al (2007) ROS mediates baicalininduced apoptosis in human promyelocytic leukemia HL-60 cells through the expression of the Gadd153 and mitochondrial-dependent pathway. Anticancer Res, 27, 117-25.

Ma Z, Otsuyama K, Liu S, et al (2005) Baicalein, a component of Scutellaria radix from Huang-Lian-Jie-Du-Tang (HLJDT), leads to suppression of proliferation and induction of apoptosis in human myeloma cells. Blood, 105, 3312-8.

Marfe G, Tafani M, Indelicato M, et al (2009) Kaempferol induces apoptosis in two different cell lines via Akt inactivation, Bax and SIRT3 activation, and mitochondrial dysfunction. $J$ Cell Biochem, 106, 643-50.

Melyanto E, Hermawan A, Anindyajati (2012) Natural products for cancer-targeted therapy: citrus flavonoids as potent chemopreventive agents. Asian Pac J Cancer Prev, 13, 427-36.

Mertens-Talcott SU, Bomser JA, Romero C, Talcott ST, Percival SS (2005) Ellagic acid potentiates the effect of quercetin on p21waf1/cip1, p53, and MAP-kinases without affecting intracellular generation of reactive oxygen species in vitro. J Nutr, 135, 609-14.

Morales P, Haza AI (2012) Selective apoptotic effects of piceatannol and myricetin in human cancer cells. $J$ Appl
Toxicol, 32, 986-93.

Nakazato T, Ito K, Miyakawa Y, et al (2005) Catechin, a green tea component, rapidly induces apoptosis of myeloid leukemic cells via modulation of reactive oxygen species production in vitro and inhibits tumor growth in vivo. Haematol, 90, 317-25.

Nicolini F, Burmistrova O, Marrero MT, et al (2014) Induction of G2/M phase arrest and apoptosis by the flavonoid tamarixetin on human leukemia cells. Mol Carcinog, 53, 939-50.

Otsuyama KI, Ma Z, Abroun S, et al (2007) PPARbeta-mediated growth suppression of baicalein and dexamethasone in human myeloma cells. Leukemia, 21, 187-90.

Park C, Lee WS, Go SI, et al (2015) Morin, a flavonoid from Moraceae, induces apoptosis by induction of BAD protein in human leukemic cells. Int J Mol Sci, 16, 645-59.

Park JH, Jin CY, Lee BK, et al (2008) Naringenin induces apoptosis through downregulation of Akt and caspase-3 activation in human leukemia THP-1 cells. Food Chem Toxicol, 46, 3684-90.

Ramos AM, Aller P (2008) Quercetin decreases intracellular GSH content and potentiates the apoptotic action of the antileukemic drug arsenic trioxide in human leukemia cell lines. Biochem Pharmacol, 75, 1912-23.

Righeschi C, Eichhorn T, Karioti A, Bilia AR, Efferth T (2012) Microarray-based mRNA expression profiling of leukemia cells treated with the flavonoid, casticin. Cancer Genom Proteom, 9, 143-52.

Ruela-de-Sousa RR, Fuhler GM, Blom N, et al (2010) Cytotoxicity of apigenin on leukemia cell lines: implications for prevention and therapy. Cell Death Dis, 1, 19.

Russo GL, Russo M, Spagnuolo C (2014) The pleiotropic flavonoid quercetin: from its metabolism to the inhibition of protein kinases in chronic lymphocytic leukemia. Food Funct, 5, 2393-401.

Sak K, Lust H, Everaus H (2015) Cytotoxic action of flavonoids in human Burkitt's lymphoma cell lines and its antiandrogenic modulation. Int J Toxicol Pharmacol Res, 7, 108-15.

Sakao K, Fujii M, Hou DX (2009a) Acetyl derivative of quercetin increases the sensitivity of human leukemia cells toward apoptosis. Biofactors, 35, 399-405.

Sakao K, Fujii M, Hou DX (2009b) Clarification of the role of quercetin hydroxyl groups in superoxide generation and cell apoptosis by chemical modification. Biosci Biotechnol Biochem, 73, 2048-53.

Sanchez Y, Amran D, Fernandez C, de Blas E, Aller P (2008) Genistein selectively potentiates arsenic trioxide-induced apoptosis in human leukemia cells via reactive oxygen species generation and activation of reactive oxygen species-inducible protein kinases (p38-MAPK,AMPK). Int J Cancer, 123, 1205-14.

Sergediene E, Jönsson K, Szymusiak H, et al (1999) Prooxidant toxicity of polyphenolic antioxidants to HL-60 cells: description of quantitative structure-activity relationships. FEBS Lett, 462, 392-6.

Shen J, Zhang W, Wu J, Zhu Y (2008) The synergistic reversal effect of multidrug resistance by quercetin and hyperthermia in doxorubicin-resistant human myelogenous leukemia cells. Int J Hyperthermia , 24, 151-9.

Shen SC, Chen YC, Hsu FL, Lee WR (2003) Differential apoptosis-inducing effect of quercetin and its glycosides in human promyeloleukemic HL-60 cells by alternative activation of the caspase 3 cascade. J Cell Biochem, 89, 1044-55.

Shieh DE, Cheng HY, Yen MH, Chiang LC, Lin CC (2006) Baicalin-induced apoptosis is mediated by Bcl-2-dependent, but not p53-dependent, pathway in human leukemia cell 
lines. Am J Chin Med, 34, 245-61.

Spagnuolo C, Cerella C, Russo M, et al (2011) Quercetin downregulates Mcl-1 by acting on mRNA stability and protein degradation. Br J Cancer, 105, 221-30.

Spagnuolo C, Russo M, Bilotto S, et al (2012) Dietary polyphenols in cancer prevention: the example of the flavonoid quercetin in leukemia. Ann NY Acad Sci, 1259, 95-103.

Switalska M, Grynkiewicz G, Strzadala L, Wietrzyk J (2013) Novel genistein derivatives induce cell death and cell cycle arrest through different mechanisms. Nutr Cancer, 65, 874-84.

Tolomeo M, Grimaudo S, Di Cristina A, et al (2008) Galangin increases the cytotoxic activity of imatinib mesylate in imatinib-sensitive and imatinib-resistant Bcr-Abl expressing leukemia cells. Cancer Lett, 265, 289-97.

Ueda S, Nakamura H, Masutani H, et al (2002) Baicalin induces apoptosis via mitochondrial pathway as prooxidant. $\mathrm{Mol}$ Immunol, 38, 781-91.

Vargo MA, Voss OH, Poustka F, et al (2006) Apigenin-inducedapoptosis is mediated by the activation of PKCdelta and caspases in leukemia cells. Biochem Pharmacol, 72, 681-92.

Vezina A, Chokor R, Annabi B (2012) EGCG targeting efficacy of NF-kB downstream gene products is dictated by the monocytic/macrophagic differentiation status of promyelocytic leukemia cells. Cancer Immunol Immunother, 61, 2321-31.

Wang IK, Lin-Shiau SY, Lin JK (1999) Induction of apoptosis by apigenin and related flavonoids through cytochrome c release and activation of caspase- 9 and caspase- 3 in leukaemia HL60 cells. Eur J Cancer, 35, 1517-25.

Wang J, Yu Y, Hashimoto F, et al (2004) Baicalein induces apoptosis through ROS-mediated mitochondrial dysfunction pathway in HL-60 cells. Int J Mol Med, 14, 627-32.

Wang Y, Miao H, Li W, et al (2014) CXCL12/CXCR4 axis confers adriamycin resistance to human chronic myelogenous leukemia and oroxylin A improves the sensitivity of K562/ ADM cells. Biochem Pharmacol, 90, 212-25.

Wei YQ, Zhao X, Kariya Y, et al (1994) Induction of apoptosis by quercetin: involvement of heat shock protein. Cancer Res, 54, 4952-7.

Xiao J, Niu G, Yin S, et al (2014) The role of AMP-activated protein kinase in quercetin-induced apoptosis of HL-60 cells. Acta Biochim Biophys Sin, 46, 394-400.

Xu X, Zhang Y, Li W, et al (2014) Wogonin reverses multi-drug resistance of human myelogenous leukemia K562/A02 cells via downregulation of MRP1 expression by inhibiting Nrf2/ ARE signaling pathway. Biochem Pharmacol, 92, 220-34.

Yamasaki M, Mine Y, Nishimura M, et al (2013) Genistein induces apoptotic cell death associated with inhibition of the NF-kB pathway in adult T-cell leukemia cells. Cell Biol Int, 37, 742-7.

Yamasaki M, Mukai A, Ohba M, et al (2010) Genistein induced apoptotic cell death in adult T-cell leukemia cells through estrogen receptors. Biosci Biotechnol Biochem, 74, 2113-5.

Yuan Z, Long C, Junming T, et al (2012) Quercetin-induced apoptosis of HL-60 cells by reducing PI3K/Akt. Mol Biol Rep, 39, 7785-93.

Zheng J, Hu JD, Chen YY, et al (2012) Baicalin induces apoptosis in leukemia HL-60/ADR cells via possible down-regulation of the PI3K/Akt signaling pathway. Asian Pac J Cancer Prev, 13, 1119-24. 